\title{
Inner City Quality of Life: A Case Study of Community Consciousness and Safety Perceptions among Neighborhood Residents
}

\author{
Richard Lewis Jr., Joanne Ford-Robertson, Dohnyka Dennard \\ Department of Sociology, University of Texas at San Antonio, San Antonio, TX, USA \\ Email: richardlewis12@sbcglobal.net
}

How to cite this paper: Lewis Jr., R., Ford-Robertson, J. and Dennard, D. (2016) Inner City Quality of Life: A Case Study of Community Consciousness and Safety Perceptions among Neighborhood Residents. Open Access Library Journal, 3: e3128. http://dx.doi.org/10.4236/oalib.1103128

Received: October 11, 2016

Accepted: November 6, 2016

Published: November 9, 2016

Copyright $\odot 2016$ by authors and Open Access Library Inc.

This work is licensed under the Creative Commons Attribution International License (CC BY 4.0).

http://creativecommons.org/licenses/by/4.0/

\begin{abstract}
This research effort examines two aspects of quality of life within an inner city neighborhood: community connectedness and safety. Based on the current literature, it was hypothesized that inner city residents would exhibit relatively low levels of community connectedness as well as low levels of perceived safe living conditions in their community. These two broad areas were analyzed by utilizing a variety of predictor variables including age cohorts, race, gender, educational attainment, employment status, and length of community resident status. Data collection was accomplished through surveying adult residents by utilizing a systematic random sample design. The research findings suggested that resident perceptions of the neighborhood were quite different from the general assertions made about inner city neighborhoods in the extant literature. Overall, residents indicated they felt safe across a number of safety indicators with race, educational attainment, employment status, age, and length of residence in the neighborhood having relatively no influence on these perceptions. Regarding community connectedness perceptions, resident responses were quite positive. Based on the findings, the research hypothesis was not supported.
\end{abstract}

Subject Areas

Sociology

Keywords

Connectedness, Geographic Segregation, Inequality, Institutional Discrimination

\section{Introduction}

Many geographical areas within the United States are faced with challenges related to 
issues stemming from continual urbanization. This, often termed urban sprawl, is generally defined as the spreading of a city and its contiguous suburbs into rural land areas which are located at the fringes. The dynamics of growth, especially in the Sunbelt region of the United States, exhibits tremendous population expansion away from core of central cities. Suburban growth coupled with exurbs has led to urban sprawl. Recent population growth in Austin, Texas and San Antonio, Texas are contemporary examples of how suburbs, related to these cities, expand for miles nearly 360 degrees around the urban central city core.

Across the nation, growing numbers of communities are discovering links between urban sprawl and a wide range of problems: from traffic and air pollution to central city poverty, and the degradation of scenic areas [1]. This phenomenon has negative impacts on central city areas. For example, maintaining infrastructure and providing improved quality of life for residents and economic development opportunities become problematic ventures in the metropolitan central city areas. This is particularly acute among inner-city racial minority enclave neighborhoods [2]. This study focuses on quality of life issues related to inner city neighborhoods.

The purpose of this research effort is to examine two aspects of quality of life within an inner city neighborhood: community connectedness and safety. Based on the current literature, it is hypothesized that inner city residents will exhibit relatively low levels of community connectedness as well as low levels of perceived safe living conditions in their community. These two broad areas are analyzed by utilizing a variety of predictor variables including age cohorts, race, gender, educational attainment, employment status, and length of community resident status. An inner city neighborhood located in San Antonio, Texas was served as a case study for this research endeavor. Data collection was accomplished through surveying adult residents utilizing a systematic random sample design.

\section{Literature Review and Theory Application}

\subsection{Review of the Literature}

Central city and inner-city areas with high concentrations of lower socio-economic racial minority populations provide a focus into the operation of a variety of community dynamics. When considering these dynamics, poverty levels must be taken into account. Kasarda [3] found that despite economic expansion across society in the 1980s, the proportion of city residents living in poverty increased within inner-city enclaves in almost every metropolitan area in the United States. Wilson [2] would argue that inner-city neighborhoods are physically and economically separated from their metropolitan area. Two dynamics within inner-city neighborhoods that are impacted by isolation are connectedness to the community and issues of safety. Poor disadvantaged communities are often perceived as hostile environments. This is because the children of these communities are often exposed to crime, poverty, unemployment, neighborhood decay and social isolation [4]. The US Census Bureau describes two types of poor communities. One that is an impoverished area that includes census tracts with at least 
$20 \%$ of residents characterized as poor. The other is an impoverished area that includes census tracts where at least $40 \%$ of residents are characterized as poor. Both of these types are exhibit inadequate educational, medical and mental health services, and higher levels of juvenile delinquency and crime [4].

The perceptions of crime and violence, especially within inner city neighborhoods, influence the perceptions of cohesion and collective behavior among residents. Racial and economic exclusion impacts the feeling of powerlessness and the inability to impact quality of life issues within the community. Wider structural constraints and a stratified political economy can influence these perceptions of crime within communities as well as connectedness [5]. It can be extended that individuals in neighborhoods which are racially and economically isolated from the other geographic communities comprising the metropolitan area will feel less connected within their communities. Additionally, they will perceive higher levels of crime within their neighborhoods.

For many Americans, the ghetto or the inner city is a dangerous enclave which is typically crime ridden, impoverished, drug infested, and violent. Historically, as a result of ethnic and residential progression, inner city areas have expanded and threatened to consume influence nearby neighborhoods. Sustained by mass media outlets and popular culture, this view of the inner city has reached recognizable significance and has served as a powerful source for maintaining prejudice, stereotyping, and discrimination [6].

As the Civil Rights Movement climaxed in the late 1960s and urban rebellions occurred in inner city areas across the United States, the term ghetto became interchangeable with words and ideas such as combativeness and violence [6]. During this time period, substantial police authority was applied to suppress conflict, inner city residents were killed or injured, and others were left without homes [6]. Therefore, the view of the inner city evolved into one that is isolated from other urban communities and it segregates lower socio-economic minorities from their middle class and professional class counterparts.

Inner city communities are often characterized by race composition, urban isolation, and relative poverty. In the United States, ghettos are understood to consist of primarily minority peoples living in urban neighborhoods that have a high concentration of poverty. This high concentration of poverty is linked with behavior and attitudes that some may consider deviant, but are also widely perceived as a threat to the freedom, property and safety of others. However, it should be emphasized that that most inner city residents respect the law enforcement, accept conventional ideas of morality and make an effort to conform to mainstream standards of public and private conduct. However, areas of high poverty that have few good employment opportunities and subpar school systems push some residents into contemplating illegal means for obtaining sustainable personal income [7].

Many theories arise concerning the relationship between crime and poverty. One theoretical model posits an accelerating increase effect of poverty on crime. Theories developed by William Julius Wilson and Douglas Massey and Nancy Denton stress the negative effects of poverty and crime on quality of life within the inner city. These 
theoretical models note race and poverty in the United States are strongly linked and difficult to separate. As a result, inner city neighborhoods become more segregated by race and poverty. This is heightened by the flight of middle class minority individuals out of the neighborhood and into surrounding suburban communities [8]. As a result, inner city neighborhoods experience a general breakdown of the positive norms embraced by middle class residents that alleviated the harmful effects of disadvantage by applying a level of social control that persuaded residents to refrain from undesirable behavior [9]. The theoretical approach perceives the absence of middle class role models as affecting the behavior of residents and brings about a cycle of disadvantage and higher crime rates [8].

\subsection{Theory of Collective Efficacy}

Much of the current literature examines issues related to connectedness among residents within neighborhoods and communities. The Theory of Collective Efficacy Poverty, initially used to understand criminal activity, can be extended to include analyzing cohesion among neighborhood residents [10]. This theory was developed as a result of analyzing dynamics within communities in which individuals experienced family disruption and high residential mobility. Anonymity and lack of social relationships among neighborhood residents are often related to issues of family stability and mobility. Increased crime and violence in the neighborhoods were related to low resident participation in community organizations and in local activities as well as low levels of social relationships. These factors contributed to further community disintegration [5].

Neighborhood collective efficacy complements and builds on the concept of Albert Bandura's theory of collective efficacy. It represents the construction of communal trust and social cohesion along with mutual expectations for intervening in support of community social control. Neighborhood collective efficacy is linked to positive outcomes in lower socio-economic communities by "decreasing crime and delinquency and increasing positive peer attachments among youth" [4].

The incidence of poverty within communities decreases the availability of resources needed to support basic institutional components which include the family, churches, schools and charitable organizations. Therefore, poverty can contribute residential instability, ethnic heterogeneity, discourage the development of long-lasting relationships, diminish social attachments, and complicate efforts to achieve common goals [11].

The perceived level of crime is often associated with interaction between neighborhood residents. According to Robert J Sampson, "murders, physical assaults and other violent acts occur less frequently in neighborhoods where residents know and trust one another, show a willingness to supervise children in public spaces, and take steps to maintain social order" [12]. Research generally shows that the safer the community is perceived to be, the more residents share common goals, values, and mutual reliance [13]. A research team headed by Sampson found that not only did collective efficacy increase sharply in communities with low crime rates; it also had a more substantial 
impact on violent crimes within neighborhoods than pervasive poverty, large numbers of first generation immigrants, or transient residence [12].

Ecological systems theory attempts to explain human behavior and its consequences within the context of social and physical environments. This theory focuses on two main ideas. The first is the exchange between an individual and their environment as they strive to acclimate and adjust into established systems, and the second is the interconnection of the many levels of an ecological system. The ecological systems theory suggests that all levels of an ecological system influence the individual, and for an individual to thrive, equilibrium between the various systems must be achieved [14].

Urie Brofenbrenner's ecological framework credits the neighborhood as a "transactional setting that directly and indirectly influences human behavior and development" [4]. He views citizen participation, the functional, deliberate involvement of individuals and groups to influence problematic conditions in underprivileged communities, as an instrument that positively impacts neighborhood problems and issues. This ecological perspective reveals how living in underprivileged communities can undesirably influence inhabitants and how resident participation can empower and lead to positive outcomes for the community [4].

Based on the previous theoretical discussion, Collective Efficacy Theory allows for the linkage of quality of life issues to types of neighborhoods. Communities comprised of residents who perceive high levels of safety will have high levels of connectedness. Conversely, residents who perceive low levels of safety will perceive low levels of connectedness. Most of the literature suggests that the demographics of inner city neighborhoods (racial composition and socioeconomic status) influence perceptions of community safety and connectedness. A general research hypothesis is posited for guiding this case study of an inner city neighborhood.

$\mathrm{H}_{\mathrm{R}}$ : There is a direct relationship between perceptions of safety and community connectedness. Within an inner city neighborhood, residents perceive low levels of safety and low levels of connectedness.

\section{Methods}

Description of the Neighborhood. The Eastpoint ${ }^{1}$ neighborhood covers approximately $3 \frac{1}{2}$ square miles and five census tracts just east of downtown San Antonio, Texas. The San Antonio Independent School District (SAISD) serves this area with three elementary schools, one middle school and one child development center. The neighborhood is one of two traditional bases for San Antonio's African American community. The community infrastructure has been in decline for several decades (street disrepair, lighting issues, lack of sidewalks, etc.). In recent years, an area that had an African American majority relative to population composition has become more ethnically diverse. Today, Hispanic Americans represent the majority population in the target area. Over a ten-year period, the population in this area declined by $5 \%$ (see Ta-

${ }^{1}$ Eastpoint is used as pseudonym for actual neighborhoods comprising the inner city area which is the focus of this study. 
ble 1). Yet the overall population growth in San Antonio expanded by $16 \%$. The families that remained in the target community tend to be younger, poorer, and less educated in comparison to the Greater San Antonio area (see Table 1).

Sampling Design. For the purpose of this study, a stratified (proportionate) random sampling design was employed to obtain a sample for analysis. The households were divided (stratified into a single residence unit sampling frame and a multi-housing unit sampling frame). Each household was assigned a unique number. Sample elements were selected with the use of a random number generator. Proportionate weights relative to sample selection were given to single resident household and multi-family households. Therefore, each element had a statistically known chance of being selected as part of the sample. The advantages associated with this sampling design were that it required minimum knowledge of population and it is free of possible classification errors. The major disadvantage related to this type of sampling design was that larger sampling errors may occur due to controlling for type of household [15] [16].

The sampling unit was composed of households. These households were divided into two sub-sampling groups; a single-family household group and a multi-family household group. A list was generated for both groupings. Census Tracts, from the United States Bureau of the Census which comprise the EPN target area, was used to generate a comprehensive household address listing. The stratified random sampling design would ensure that heterogeneous neighborhood factors would not be minimized. Addi-

Table 1. Profile of the Eastpoint neighborhood, 2000 and 2010.

\begin{tabular}{|c|c|c|}
\hline Eastpoint Census Tract Information & $\underline{2000}$ & $\underline{2010}$ \\
\hline African-American & $6286(34.0 \%)$ & $4188(23.9 \%)$ \\
\hline Hispanic & $10,351(56.2 \%)$ & $11,926(68.1 \%)$ \\
\hline White (Non-Hispanic) & $821(4.5 \%)$ & $1120(6.4 \%)$ \\
\hline Other (Racial and Ethnic groups) & $973(5.3 \%)$ & $282(1.6 \%)$ \\
\hline Total Population & 18,431 & 17,516 \\
\hline American Communities Survey 2006-2010 (5-year estimates) & Eastpoint & $\underline{\text { San Antonio }}$ \\
\hline Foreign born & $19 \%$ & $14 \%$ \\
\hline Employed (>16 years old) & $51 \%$ & $59 \%$ \\
\hline Owner-occupied housing & $46 \%$ & $59 \%$ \\
\hline Children in poverty & $56 \%$ & $27 \%$ \\
\hline Median household income & 21,491 & 43,152 \\
\hline Adults without a high school diploma & $39 \%$ & $21 \%$ \\
\hline Children 0 - 19 years of age & $32 \%$ & $30 \%$ \\
\hline Average family size & 3.478 & 3.43 \\
\hline Males & $49 \%$ & $49 \%$ \\
\hline Females & $51 \%$ & $51 \%$ \\
\hline
\end{tabular}


tionally, low population density areas were not over-sampled. Prior to finalizing the sample, researchers verified the validity of each address. By utilizing household as a sampling unit, getting a generalizable microcosm of the neighborhood was ensured. For each household chosen, an individual, who was at least 18 years of age, was chosen randomly for interview.

A comprehensive listing of approximately 4631 addresses was used to generate a sample of 1200 household units. A final survey sample of 633 respondents was obtained and the surveying was conducted in June 2015. The completion [response] rate was $52 \%$. The sampling error associated with these numbers is approximately $\pm 5 \%$ at a confidence level of 95\% [17].

A survey questionnaire was administered to participants in June 2015. The instrument was used in two previous survey efforts (2013 and 2014). The survey items yielded generally consistent information across each survey period. This consistency of item measurement provides strong evidence of survey item reliability.

\section{Study Findings}

\subsection{Demographic Overview of Eastpoint}

The resident survey information revealed some interesting demographic distributions. Racial and gender composition showed that the community was quite heterogeneous. Table 2 shows that $57 \%$ of the residents were female. With respect to racial composition, $51 \%$ were Hispanic, 38\% were African American, and 6\% were White.

Educational attainment and employment status are two important descriptive variables associated with the EPN target area. Table 2 shows that the highest percentage of educational attainment completed in the community was high school with $30 \%$ of respondents obtaining a diploma. Roughly $21 \%$ of respondents completed some colleges or trade schools while only $5 \%$ completed community colleges, and $7 \%$ of community members earned a college degree. With respect to employment status, approximately $52 \%$ of community respondents said they were employed (either full-time or part-time). Another $27 \%$ were not working with about $19 \%$ stating they were retired.

Table 2 reflects information related to the age of the survey participant, resident information, and family arrangement issues. In the Eastside Promise Neighborhood target area, the average age of the respondent was 48 years of age. The youngest respondent was 18 years of age and the oldest respondent was 98 years of age. The average number of years a respondent lived in the neighborhood was 15 years, with the maximum number of years being 72 years.

\subsection{Perceptions of Community Consciousness and Safety}

The study revealed very positive resident perceptions of quality of life within the community. The findings, regarding connectedness, demonstrated that the majority of the residents believed they are part of Eastpoint. Over 53\% said they felt like they are members of the community and another $65 \%$ indicated they belong to the neighborhood. Moreover, nearly 55\% perceived they are connected to the Eastpoint community (see Table 3). 
Table 2. Summary of Eastpoint resident demographic profile, 2015.

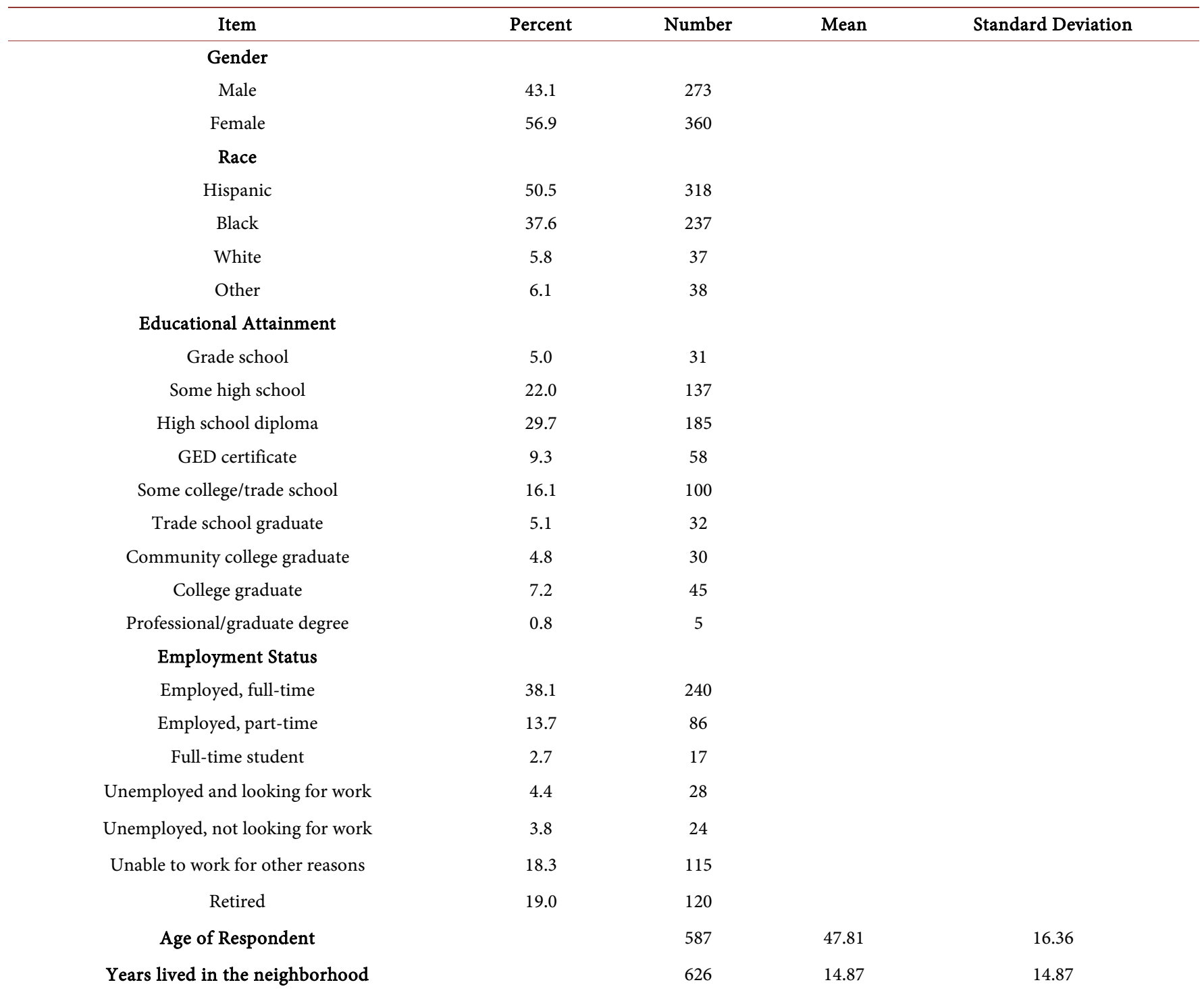

Table 3. Resident perceptions of connectedness and safety in Eastpoint, 2015.

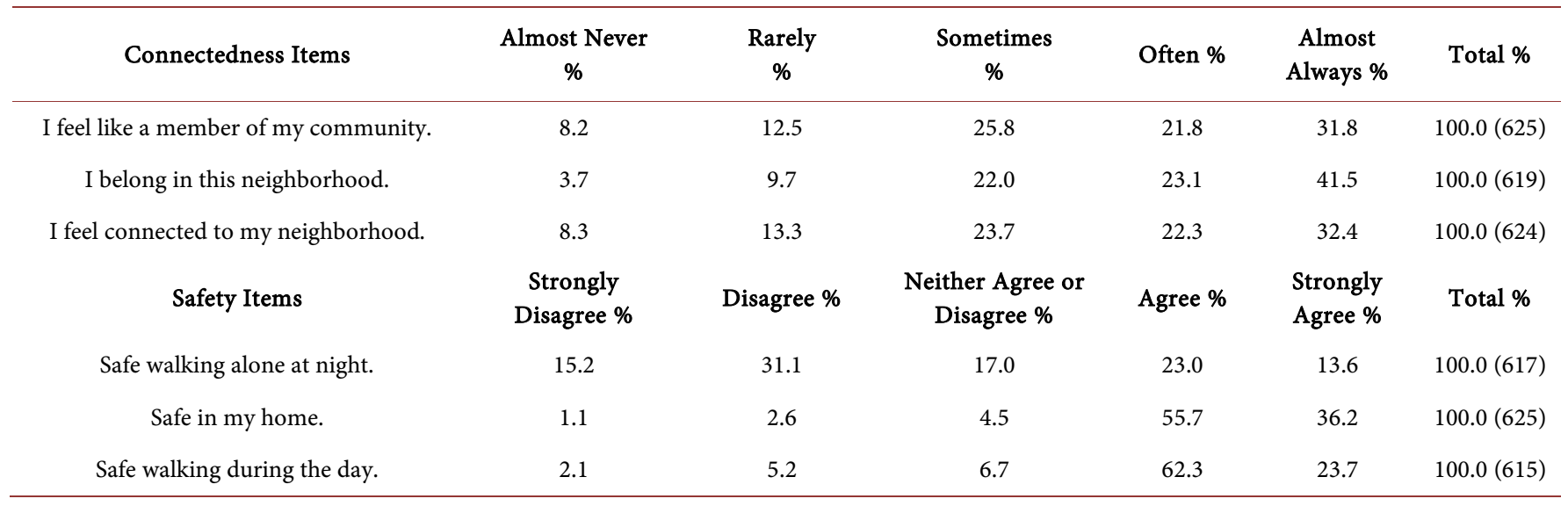


Residents provided views indicating they generally perceive Eastpoint as a safe place to live. Table 3 illustrates that $92 \%$ said they feel safe in their homes and roughly $86 \%$ indicated they feel safe walking in the neighborhood during the day. Finally, only $37 \%$ believed it is safe to walk in community in the evening.

There were important relationships discovered between community connectedness perceptions and perceptions of safety. Table 4 points out that moderate positive correlations existed between these items. Generally, residents who indicated they felt safe in the neighborhood tended to say they felt connected to the community. Respondents who perceived they were safe in their homes said they were members of the community and were connected to the neighborhood. Residents indicating the felt safe walking in the neighborhood tended to feel they were members and belonged to the neighborhood. Similar responses were found for those who felt safe walking in the community at night.

Table 5 analyzes the correlations between issues of community connectedness and safety, and gender, race, educational attainment, employment status, age and length of residence. Spearman correlation analysis was used to understand the nature of the relationship between variables. According to the information, there was no relationship between race/ethnicity and feeling like a member of the community or perceptions of safety in the neighborhood.

Table 4. Summary of spearman correlations between selected community connectedness and safety items, 2015.

\begin{tabular}{ccccccc}
\hline Variables & Member & Belong & Connected & Night & Home & Walk \\
\hline Member & - & $0.671^{\star *}$ & $0.755^{\star *}$ & $0.226^{\star *}$ & $0.299^{\star *}$ & $0.307^{\star *}$ \\
Belong & & - & $0.709^{* *}$ & $0.186^{\star *}$ & $0.301^{\star *}$ & $0.339^{\star *}$ \\
Connected & & & - & $0.235^{\star *}$ & $0.286^{\star *}$ & $0.330^{\star *}$ \\
Night & & & & - & $0.269^{\star *}$ & $0.385^{\star *}$ \\
Home & & & & & - & $0.557^{\star}$ \\
Walk & & & & & & - \\
\hline
\end{tabular}

${ }^{\star}$ Probability level is $<0.05$; ${ }^{* *}$ Probability level is $<0.01$.

Table 5. Summary of spearman correlations between selected community connectedness and safety items and gender, race, educational attainment, employment status, age, and length of residence, 2015.

\begin{tabular}{ccccccccc}
\hline Variables & Gender & Hispanic & Black & White & Education & Employment & Age & Length \\
\hline Member & -0.056 & -0.009 & 0.067 & -0.047 & $-0.098^{*}$ & -0.026 & $0.128^{* *}$ & $0.178^{* *}$ \\
Belong & $-0.105^{* *}$ & 0.065 & 0.007 & -0.043 & -0.078 & -0.032 & $0.163^{* *}$ & $0.211^{* *}$ \\
Connected & -0.063 & 0.021 & 0.028 & -0.035 & $-0.103^{*}$ & -0.041 & $0.136^{* *}$ & $0.182^{\star *}$ \\
Night & $-0.155^{* *}$ & -0.065 & 0.072 & 0.056 & 0.045 & 0.055 & -0.033 & -0.015 \\
Home & -0.076 & 0.004 & 0.041 & -0.043 & 0.033 & -0.034 & 0.016 & 0.074 \\
Walk & $-0.147^{* *}$ & 0.036 & 0.002 & 0.003 & 0.027 & $0.082^{*}$ & -0.050 & 0.011 \\
\hline
\end{tabular}

${ }^{\star}$ Probability level is $<0.05$; ${ }^{*}$ Probability level is $<0.01$. 
In terms of gender, there was a low positive association concerning residents feeling like they belong in the neighborhood and a low negative association regarding resident perception of safety while walking alone in the neighborhood. There was a negligible association between educational attainment and resident feelings of safety (walking alone, feeling safe in the home), and belonging in the neighborhood, and a low negative correlation between educational attainment and feeling connected to the neighborhood. This shows that the higher the educational attainment, the less likely the respondent felt connected to the community.

Employment status had no effect on resident perceptions of community connectedness and safety. There was a low positive association between age and feeling like a member of the community. The older the resident the more likely they felt connected to the community and their neighborhood. Similarly, length of residence shows a low positive correlation regarding resident perceptions of community connectedness. There was a negligible correlation between age of resident and feelings of safety, as well as length of residence and perceptions of safety.

\section{Study Conclusions}

The research findings suggest that Eastpoint resident perceptions are quite different from the general assertions made about inner city neighborhoods in the extant literature. Overall, residents indicated they felt safe across a number of safety indicators with race, educational attainment, employment status, age, and length of residence in the neighborhood having relatively no influence on these perceptions. With respect to gender, women exhibited lower levels of perceived safety in comparison to men.

Regarding community connectedness perceptions, resident responses were quite positive. Older residents and those who have lived in the Eastpoint longer tended to exhibit higher levels of connectedness. Additionally, a weak relationship was found between educational attainment and connectedness perceptions. Those with higher educational attainment tended to express lower levels of community connectedness. Employment status, gender, and race did not impact connectedness perceptions.

Our research hypothesis posited there was a direct relationship between perceptions of safety and community connectedness. Within an inner city neighborhood, residents perceive low levels of safety and low levels of connectedness. Based on the findings, the research hypothesis was not supported. It should be noted that this research demonstrated a perceived linkage between safety and community connectedness levels. We did find, for the inner city neighborhood, higher levels of perceptions of safety were positively correlated with higher levels of community connectedness as posited by Collective Efficacy Theory. Many of the studies found in the existing literature suggest that the demographics of inner city neighborhoods (racial composition and socioeconomic status) negatively influence perceptions of community safety and connectedness. This research effort discovered findings contradicting these asserted negative influences.

\section{References}

[1] Ewing, R., Pendall, R. and Chen, D (2002) Measuring Sprawl and Its Impact. Smart Growth 
America, Washington DC.

[2] Wilson, W.J. (2009) More Than Just Race: Being Black and Poor in the Inner City. Norton, New York.

[3] Kasarda, J.D. (1993) Inner-City Concentrated Poverty and Neighborhood Distress: 1970 to 1990. Housing Policy Debate, 4, 253-302. http://dx.doi.org/10.1080/10511482.1993.9521135

[4] Ohmer, M.L. (2010) How Theory and Research Inform Citizen Participation in Poor Communities: The Ecological Perspective and Theories on Self- and Collective Efficacy and Sense of Community. Journal of Human Behavior in the Social Environment, 20, 1-19. http://dx.doi.org/10.1080/10911350903126999

[5] Sampson, R.J., Raudenbush, S.W. and Earls, F. (1997) Neighborhoods and Violent Crime: A Multilevel Study of Collective Efficacy. Science, 277, 918-924. http://dx.doi.org/10.1126/science.277.5328.918

[6] Anderson, E. (2012) The Iconic Ghetto. The Annals of the American Academy of Political and Social Science, 642, 8-24. http://dx.doi.org/10.1177/0002716212446299

[7] Shelby, T. (2007) Justice, Deviance, and the Dark Ghetto. Philosophy \& Public Affairs, 35, 126-160. http://dx.doi.org/10.1111/j.1088-4963.2007.00106.x

[8] Hipp, J.R. and Yates, D.K. (2011) Ghettos, Thresholds, and Crime: Does Concentrated Poverty Really Have an Accelerating Increasing Effect on Crime? American Society of Criminology, 49, 955-990.

[9] Sampson, R.J. and Wilson, W.J. (1995) Toward a Theory of Race, Crime, and Urban Inequality. In: Hagan, J. and Peterson, R.D., Eds., Crime and Inequality, Stanford University Press, Stanford.

[10] Sampson, R.J. (1995) The Community, 193-216. In: Wilson, J.Q. and Petersilia, J., Eds., Crime, ICS Press, San Francisco.

[11] Browning, C.R. (2002) The Span of Collective Efficacy: Extending Social Disorganization Theory to Partner Violence. Journal of Marriage and Family, 64, 833-850. http://dx.doi.org/10.1111/j.1741-3737.2002.00833.x

[12] Bower, B. (1997) United Neighbors Take a Bite out of Crime. Science News, 152, 101. http://dx.doi.org/10.2307/3981006

[13] Uchida, C.D., Swatt, M.L., Solomon, S.E. and Verano, S. (2014) Neighborhoods and Crime: Collective Efficacy and Social Cohesion in Miami-Dade County. Report Prepared for the U.S. Department of Justice.

[14] Booth, J.M. and Anthony, E.K. (2015) Examining the Interaction of Daily Hassles Across Ecological Domains on Substance Use and Delinquency among Low-Income Adolescents of Color. Journal of Human Behavior in the Social Environment, 25, 810-821. http://dx.doi.org/10.1080/10911359.2015.1027026

[15] Babbie, E. (2012) The Practice of Social Research, 11th Edition, Wadsworth Publishing, Belmont.

[16] Dishi, S.M. (2003) How to Conduct In-Person Interviews for Surveys. 2nd Edition, Sage Publication, Thousand Oaks.

[17] Fink, A. (1995) How to Design Surveys. Sage Publication, Thousand Oaks. 
Submit or recommend next manuscript to OALib Journal and we will provide best service for you:

- Publication frequency: Monthly

- 9 subject areas of science, technology and medicine

- Fair and rigorous peer-review system

- Fast publication process

- Article promotion in various social networking sites (LinkedIn, Facebook, Twitter, etc.)

- Maximum dissemination of your research work

Submit Your Paper Online: Click Here to Submit

Or Contact service@oalib.com 